\title{
Posição na fratria e personalidade ${ }^{1}$
}

\author{
Sibling position and personality
}

\author{
Otília Monteiro FERNANDES² \\ Madalena ALARCÃO3 \\ JoséVasconcelos RAPOSO²
}

\begin{abstract}
Resumo
Este estudo procurou investigar a forma como a presença ou a ausência de irmãos influencia a personalidade. O lugar que cada um ocupa na família proporciona experiências diversificadas; alguns aspectos da personalidade, conseqüentemente, podem ser distintos consoante a posição fraternal do sujeito considerado. A amostra foi constituída por 1.142 estudantes universitários, 874 do sexo feminino e 268 do masculino. As análises estatísticas realizadas demonstraram a existência de diferenças de personalidade entre os sujeitos que ocupam uma das quatro principais posições fraternais: únicos, mais velhos, mais novos e do meio. Nomeadamente, nas facetas da rectidão, altruísmo e complacência (do domínio da Amabilidade), obediência ao dever e deliberação (do domínio da Conscienciosidade) e hostilidade (do domínio do Neuroticismo). Os resultados foram discutidos à luz das teorias dos principais estudiosos da fratria, concretamente, Adler, Toman e Sulloway.
\end{abstract}

Unitermos: posição na fratria; filho único; personalidade.

\begin{abstract}
This study addresses the presence or absence of siblings influence on the personality. The position occupied in the family provides diversified experiences - consequently, some aspects of the personality are also different and individual. This sample includes 1142 university students: 874 females and 268 males. The statistical analysis indicated the existence of personality differences among the subjects that occupy the main sibling positions: the only, the oldest, theyoungest and the middle. These were the facets of detachment: straightforwardness, altruism and compliance (in the domain of Agreeableness), dutifulness and deliberation (in the domain of Conscientiousness) and angry hostility (in the domain of Neuroticism). The results were discussed through Adler, Toman and Sulloway's siblings theories.
\end{abstract}

Uniterms: sibling position; only child; personality.

Tudo começa em casa (Winnicott, 1989). Ou, por assim dizer, é na família, tenha ela a configuração que tiver, que o desenvolvimento do ser humano se inicia. Por ser o primeiro contexto desenvolvimental, é o mais significativo na ontogenia. Com efeito, é na família que sentimos os primeiros amores e os primeiros ódios, com ela fazemos as primeiras aprendizagens - que fazem parte do processo de socialização -, e é lá que começa o desenvolvimento da nossa personalidade. Parte significativa de cada um de nós construir-se-á, então, a partir das aprendizagens realizadas no quadro familiar, sobretudo das relações com os pais e os irmãos.

$\mathbf{v} \mathbf{v} \boldsymbol{\nabla}$

1 Artigo elaborado a partir da dissertação de doutoramento de O.M. FERNANDES, intitulada "Fratria e personalidade". Universidade deTrás-os-Montes e Alto Douro (UTAD). Portugal, 2000.

2 Universidade de Trás-os-Montes e Alto Douro, Departamento de Educação e Psicologia. Quinta dos Prados, Apartado 1013, 5001-801, Vila Real, Portugal. Correspondência para/Correspondenceto: O.M. FERNANDEZ.E-mail: <otiliamf@gmail.com>.

3 Universidade de Coimbra, Faculdade de Psicologia e de Ciências da Educação. Coimbra, Portugal. 
Pressupõe-se que essas primeiras experiências relacionais determinarão, em grande parte, as relações sociais posteriores.

Os investigadores familiares têm dado ênfase, sobretudo, às diferenças entre famílias (por exemplo, estudando o funcionamento familiar) mas têm-se interessado menos pelas relações existentes no seu interior. A pouca investigação intrafamiliar tem incidido, quase exclusivamente, sobre as relações pais-filhos (e, nessas, mais sobre a influência dos primeiros sobre os segundos do que o inverso) e, muito raramente, sobre as relações no seio da fratria. Como refere Gayet (1993, p.9)"A literatura psicológica é estranhamente muda sobre as relações fraternais" e, na psicanálise, o laço entre os irmãos tem sido "o parente pobre", embora ele nos reconduza "ao coração da intersubjectividade edipiana!" (Assoun, 1998, p.5).

Mas uma parte importante da família são os irmãos, ou a ausência deles (como é o caso dos filhos únicos). Se o parental é o primeiro contexto relacional para os filhos únicos e para os primogênitos, o contexto fraternal pode igualmente ser um dos primeiros para os secundogênitos ... e ultimogênitos, pois os irmãos já lá estão quando eles nascem. E para os primogênitos, até pelo fato de serem destronados, a fratria que se lhes segue torna-se logo um contexto de grande importância para o seu desenvolvimento posterior. Em média, o segundo filho nasce poucos anos depois do primeiro e, por isso, a fratria torna-se um contexto precoce na vida da maioria de nós. Sobretudo quando as crianças têm idades muito próximas, o fato de freqüentarem a mesma creche, o mesmo maternal e a mesma escola faz com que elas se mantenham em contato durante grande parte do dia e, portanto, durante mais horas do que aquelas que permanecem com os progenitores. Por outro lado, a relação entre os irmãos é, normalmente, a mais extensa no tempo:"os pais morrem mais cedo, os cônjuges vêm mais tarde, os amigos mudam" (Meynckens-Fourez, 1999, p.37). Mas não é só durante a infância que se verifica uma influência recíproca e determinante entre os irmãos. Mesmo depois, ao longo de toda a vida, longe ou perto, a marca indelével dessas relações passadas parece continuar a fazer sentir-se e a co-orientar o destino de cada um. As primeiras experiências com os nossos irmãos moldam, ainda hoje, a nossa maneira de agir, de pensar ou de nos considerarmos a nós mesmos (Faber \& Mazlish, 1995).
De que família e, especificamente, de que fratria falamos hoje? Obrigatoriamente, das múltiplas formas de família (e, conseqüentemente, de fratrias) que atualmente existem. Podemos dizer, quanto a isso, que são duas as maiores preocupações para os estudiosos da família: as inúmeras mudanças na estrutura familiar e a redução das fratrias. Um e outro fenômeno estão intimamente ligados e podem ser vistos como resultado de profundas transformações ocorridas na sociedade: o aumento da taxa de divórcio e do número de mulheres no mundo do trabalho, o baixo índice de nupcialidade e de natalidade, a importância crescente que tem sido dada à infância.

Com a alteração nas famílias foi e ainda é a própria situação dos filhos que foi e é alterada. Aliás, é o inverter da perspectiva clássica do modo de olhar a família: a família nuclear define-se a partir da união de dois progenitores; as redes das famílias recompostas parecem ser mais facilmente compreendidas a partir dos laços e territórios definidos pelos filhos (Kellerhals \& Roussel, 1987).

A redução das fratrias tende a aumentar a intensidade das relações entre os irmãos, a sua interdependência, elevada a um nível máximo em situações de crise, como ocorre durante o processo de divórcio dos pais e, como muitas vezes agora acontece, aquando da entrada de um grupo de irmãos numa nova família (onde existem, ou não, outras crianças com as quais há que partilhar um novo espaço e a atenção do novo casal). Nessas situações, cada vez mais correntes, de fragmentação familiar, as relações fraternais podem ser vistas, como diz Almodovar (1986, p.3), como uma "ilha de estabilidade" ou, até, de "permanência familiar". Essa nova problemática familiar conduziu, recentemente, a um aumento de estudos sobre a fratria, embora ela continue, mesmo assim, a ser um dos tópicos menos abordados dentro do tema família.

Todavia, desde há muitos anos, psicanalistas e psicólogos eminentes, como Adler, Freud e Piaget, mesmo que só em breves linhas, salientaram a importância do contexto fraternal no desenvolvimento individual.

Com efeito, foi Alfred Adler (1870-1937) o primeiro a definir, em traços gerais, a personalidade correspondente a cada uma das principais posições fraternais. Esse discípulo de Freud - um dos primeiros 
mas, também, um dos seus primeiros dissidentes - é considerado como o pioneiro no estudo das relações fraternais. Foi ele o primeiro a assinalar a constelação de irmãos como o primeiro "microcosmo" social, anterior à vida escolar e social, onde a criança, na relação com os iguais que são os seus irmãos, pode aprender a desenvolver as suas capacidades cooperativas e a preparar-se para enfrentar os problemas da vida (Arranz Freijo, 1989). Ou seja, para Adler, é na relação com a família e, em particular, com os irmãos que se começa a desenvolver o sentimento social (ou de comunidade)que é fundamental para o desenvolvimento do caráter. Adler (1926/1984) refere, nomeadamente, que a posição na fratria é de tal modo importante na modelação do caráter individual que é possível reconhecer rapidamente, desde que tenhamos experiência suficiente, se um dado indivíduo é primogênito, único, caçula, etc.
O autor não fez um estudo sistematizado da questão fraternal mas definiu, em traços gerais, a personalidade do filho mais velho, do segundo, do meio, do mais novo, do filho único, etc., tal como podemos constatar numa breve simplificação da teoria adleriana apresentada por Stein (2006) (Tabela 1). Como podemos ver nessa tabela, Adler, para além de definir as principais posições fraternais, referiu-se, ainda, a outras posições fraternais, tais como: único rapaz entre meninas, gêmeos, fratrias só de meninas. Observava, assim, que não era só a ordem de nascimento mas também o sexo e o número de irmãos que influíam na personalidade.

Depois de Adler, o autor que mais exaustivamente definiu o perfil de personalidade característico das diversas posições fraternais (tendo em conta a ordem de nascimento, o sexo, as diferenças de idade e o tamanho da fratria) - bem como as diversas

Tabela 1. Síntese da teoria de Adler sobre as posições fraternais (Stein, 2006)

\begin{tabular}{|c|c|c|}
\hline Posição & Situação familiar & Características das crianças \\
\hline Único & $\begin{array}{l}\text { O nascimento é um milagre. Os pais não têm experiência } \\
\text { prévia. Retém } 200 \% \text { da atenção de ambos os pais. Pode } \\
\text { tornar-se rival de um dos pais. Pode ser superprotegido } \\
\text { e mimado. }\end{array}$ & $\begin{array}{l}\text { Gosta de ser o centro da atenção dos adultos. Muitas vezes tem } \\
\text { dificuldade em partilhar com as outras crianças. Prefere a } \\
\text { companhia dos adultos e utiliza a linguagem deles. }\end{array}$ \\
\hline Mais velho & $\begin{array}{l}\text { Destronado pelo filho seguinte. Tem de aprender a } \\
\text { partilhar. As expectativas dos pais são geralmente muito } \\
\text { altas. Muitas vezes são-lhe dadas responsabilidades e } \\
\text { espera-se que dê o exemplo. }\end{array}$ & $\begin{array}{l}\text { Pode tornar-se autoritário ou disciplinador. Sente que o poder é } \\
\text { o seu direito natural. Pode tornar-se prestável desde que } \\
\text { encorajado. Pode tornar-se pai depois do nascimento do irmão } \\
\text { seguinte. }\end{array}$ \\
\hline Segundo & $\begin{array}{l}\text { Tem alguém que lhe dá o exemplo. Tem sempre alguém } \\
\text { na frente. }\end{array}$ & $\begin{array}{l}\text { É mais competitivo, deseja alcançar o irmão mais velho. Pode } \\
\text { tornar-se um rebelde ou tentar superar toda a gente. A } \\
\text { competitividade pode descambar em rivalidade. }\end{array}$ \\
\hline Do meio & $\begin{array}{l}\text { Está ensanduichado. Pode ser forçado a sair de uma } \\
\text { posição de privilégio e significado. }\end{array}$ & $\begin{array}{l}\text { Pode ser equilibrado, com uma atitude de tanto faz. Pode ter } \\
\text { problemas em encontrar um lugar ou tornar-se o combatente } \\
\text { da injustiça. }\end{array}$ \\
\hline Mais novo & $\begin{array}{l}\text { Tem muitas mães e pais. Os irmãos mais velhos tentam } \\
\text { educá-lo. Nunca é destronado. }\end{array}$ & $\begin{array}{l}\text { Quer ser maior do que os outros. Pode ter grandes planos que } \\
\text { nunca passam disso. Pode ficar o bebê. Freqüentemente é } \\
\text { mimado. }\end{array}$ \\
\hline Gêmeos & $\begin{array}{l}\text { Um é mais forte ou ativo. Os pais podem ver um como o } \\
\text { mais velho. }\end{array}$ & $\begin{array}{l}\text { Podem ter problemas de identidade. O mais forte pode tornar- } \\
\text { se o líder. }\end{array}$ \\
\hline "Filho fantasma" & $\begin{array}{l}\text { A criança que nasce após a morte do primeiro filho pode } \\
\text { ter um fantasma à frente dela. A mãe pode tornar-se } \\
\text { superprotetora. }\end{array}$ & $\begin{array}{l}\text { Esta criança pode explorar a superpreocupação da mãe com o } \\
\text { seu bem-estar, pode tornar-se rebelde e protestar ao sentir-se } \\
\text { comparado com uma memória idealizada. }\end{array}$ \\
\hline Filho adotivo & $\begin{array}{l}\text { Os pais podem sentir-se tão agradecidos por terem um } \\
\text { filho que o mimam. Podem tentar compensá-lo pela } \\
\text { perda dos seus pais biológicos. }\end{array}$ & $\begin{array}{l}\text { Esta criança pode tornar-se muito mimada e exigente. } \\
\text { Eventualmente pode criar ressentimentos ou idealizar os seus } \\
\text { pais biológicos. }\end{array}$ \\
\hline $\begin{array}{l}\text { Único rapaz entre } \\
\text { meninas }\end{array}$ & Usualmente está com mulheres, se o pai estiver ausente. & $\begin{array}{l}\text { Pode tentar provar que é o homem da família, ou tornar-se } \\
\text { efeminado. }\end{array}$ \\
\hline $\begin{array}{l}\text { Única menina } \\
\text { entre rapazes }\end{array}$ & Os irmãos mais velhos podem agir como protetores. & $\begin{array}{l}\text { Pode tornar-se muito feminina, ou uma maria-rapaz e superar } \\
\text { os irmãos. Pode tentar agradar ao pai. }\end{array}$ \\
\hline Só rapazes & $\begin{array}{l}\text { Se a mãe desejasse uma menina, pode vesti-lo como se } \\
\text { assim fosse. }\end{array}$ & $\begin{array}{l}\text { A criança pode tirar proveito do papel designado ou protestar } \\
\text { vigorosamente. }\end{array}$ \\
\hline Só meninas & Pode ser vestida como um rapaz. & $\begin{array}{l}\text { A criança pode tirar proveito do papel designado ou protestar } \\
\text { vigorosamente. }\end{array}$ \\
\hline
\end{tabular}


situações problemáticas (por exemplo, as perdas por morte) que podem alterar a posição fraternal dos indivíduos - foi o também austríaco Toman (1959, 1993, 1995). A teoria das constelações familiares de Toman é, aliás, em nossa opinião, uma das propostas mais abrangentes sobre fratria e personalidade.

Da revisão feita sobre o tema, constatamos certa discrepância nos resultados dos diversos estudos, sobretudo resultantes das diferentes metodologias utilizadas. Com efeito, muitos deles atenderam, exclusivamente, à ordem de nascimento (excluindo variáveis como o sexo dos irmãos e a diferença de idades entre eles, por exemplo) e utilizaram diferentes instrumentos para avaliar a inteligência e a personalidade dos irmãos (que medem, muitas vezes, aspectos divergentes dessas expressões humanas). Tudo isso dificulta, obviamente, a comparação entre as várias investigações que têm sido feitas sobre esse aspecto.

A nossa investigação pretendeu contribuir, por pouco que fosse, para esclarecer algumas das malhas que a fratria tece. Em Portugal, tanto quanto nos foi e é dado conhecer, esse é o primeiro estudo na área.

Sendo um tema tão inexplorado, muitos caminhos se abriram para o nosso trabalho. Entre eles, o de perceber quanto a personalidade de cada um de nós é influenciada pelos indivíduos com quem passamos longos anos e que nos acompanham desde a nossa infância: os nossos irmãos. Efetuamos vários estudos empíricos no intuito de perseguirmos esse objetivo. Num deles, analisamos diferentes variáveis sociobiográficas e tentamos apurar, especificamente, se a posição fraternal é uma das que contribui para a variação numa ou em várias das trinta facetas da personalidade (tal como ela é medida pelo NEO Personality Inventory - Revised (NEO PI-R), que descreveremos adiante). É esse estudo que apresentaremos aqui de forma reduzida (o restante pode ser consultado em Fernandes, 2000, 2002 e 2005).

\section{Métodos}

\section{Participantes}

A amostra foi constituída por 1.142 estudantes universitários, 874 (76,5\%) do sexo feminino e 268 (23,5\%) do masculino, solteiros, de raça branca e não gêmeos, e com idade média de 21,28 anos.

Dado que a fratria real nem sempre corresponde à fratria com a qual se viveu (por exemplo: há meiosirmãos com os quais nunca se viveu ou, nas fratrias grandes, alguns dos irmãos saíram de casa ou morreram antes do nascimento dos sujeitos), compreende-se que é a fratria vivida que nos interessa, isto é, os irmãos que viveram com o sujeito durante toda a sua vida ou durante parte importante dela. Por isso, em todas as variáveis relativas à fratria, consideramos sempre a fratria vivida e não a fratria real.

Assim, levando em conta a fratria vivida, agrupamos os sujeitos nos quatro grupos fraternais seguintes: filhos únicos, irmãos mais velhos, irmãos mais novos e irmãos do meio (Tabela 2) - variável que adiante designaremos como FRATRIA4.

\section{Instrumentos}

Com o intuito de medirmos as condições sociobiográficas e a personalidade dos sujeitos, administramos aos estudantes dois instrumentos: o Questionário Sociobiográfico (QSB) e o NEO Personality Inventory-Revised (NEO PI-R).

O QSB é um questionário que construímos baseando-nos no Social Environment Questionnaire de Toman (1993). Inquire o sujeito sobre a sua condição (sexo, raça, religião, nacionalidade, curso que freqüenta, atividade profissional, orientação política, idade, mudanças de escola e residência, doenças e hospitalizações, número de filhos) e sobre a sua própria história familiar (posição na fratria, vivência no passado com os pais e/ou substitutos e com os irmãos, agregado familiar atual); sobre a condição dos seus pais (e/ou substitutos) e dos seus irmãos (número, idade, sexo,

Tabela 2. Distribuição dos sujeitos, por sexo, nos quatro grupos fraternais.

\begin{tabular}{|c|c|c|c|c|}
\hline \multirow{3}{*}{ Grupos } & \multicolumn{4}{|c|}{ Sexo } \\
\hline & \multicolumn{2}{|c|}{ Feminino } & \multicolumn{2}{|c|}{ Masculino } \\
\hline & $\mathrm{n}$ & $\%$ & $n$ & $\overline{\%}$ \\
\hline Filhos únicos & 101 & 8,8 & 33 & 2,9 \\
\hline Irmãos mais velhos & 315 & 27,6 & 102 & 8,9 \\
\hline Irmãos mais novos & 327 & 28,6 & 89 & 7,8 \\
\hline Irmãos do meio & 131 & 11,5 & 44 & 3,9 \\
\hline Total & 874 & 76,5 & 268 & $\overline{23,5}$ \\
\hline
\end{tabular}


profissão, doenças ou deficiências), bem como sobre a posição fraternal daqueles e as perdas sofridas. Grosso modo, pode considerar-se o QSB como uma espécie de questionário anamnésico com o objetivo principal de reconstruir a constelação familiar na qual o sujeito viveu, desde que nasceu até agora.

O NEO PI-R de Costa e McCrae (1992), aferido para a população portuguesa por Lima (1997), é um inventário de personalidade que operacionaliza o modelo dos cinco principais fatores (ou domínios): o Neuroticismo (N), a Extroversão (E), a Abertura à Experiência ( $\mathrm{O}$, de Openness to Experience), a Amabilidade (A) e a Conscienciosidade (C). Cada um deles é constituído por seis facetas, respectivamente: N1 ansiedade, N2 - hostilidade, N3 - depressão, N4 autoconsciência, N5 - impulsividade, N6 vulnerabilidade; E1 - acolhimento caloroso, E2 gregariedade, E3 - assertividade, E4 - actividade, E5 procura de excitação, E6 - emoções positivas; 01 fantasia, O2 - estética, O3 - sentimentos, $\mathrm{O} 4$ - ações, O5 - idéias, 06 - valores; A1 - confiança, A2 - retidão, A3 altruísmo, A4 - complacência, A5 - modéstia, A6 sensibilidade; C1 - competência, C2 - ordem, C3 obediência ao dever, C4 - esforço de realização, C5 autodisciplina, C6 - deliberação.

A definição da personalidade subjacente ao modelo dos cinco factores realça as regularidades recorrentes (os traços) e a sua organização característica em cada pessoa.

Aplica-se a adolescentes e a adultos (a partir de 17 anos de idade) que não sofram de perturbações susceptíveis de afetar a sua capacidade para completar medidas de auto-avaliação de forma fiel e válida (Lima \& Simões, 2000) individualmente ou em grupo e leva de 40 a 50 minutos, em média, a ser preenchido.

O NEO PI-R contém duzentas e quarenta afirmações/itens, sendo cada uma delas pontuada numa escala de cinco valores: de Discordo Fortemente a Concordo Fortemente. Cada faceta é avaliada por oito itens. A pontuação total de cada domínio obtém-se somando os resultados das suas respectivas seis facetas.

\section{Procedimentos}

De modo a considerarmos, conjuntamente, todas as variáveis independentes e dependentes (respectivamente, os dados do QSB e os do NEO PI-R), servimo-nos do modelo estatístico multivariado do SPSS, realizável através da opção General Linear Model multivariate (GLM).

Ou seja, ao optarmos pelo procedimento GLM o nosso objetivo era, genericamente, investigar a influência conjunta e os efeitos principais das várias variáveis independentes nas médias das variáveis dependentes.

As duas hipóteses nulas a testar eram as seguintes:

1) A posição fraternal não é uma variável significativa nesse modelo, isto é, não contribui para as variações na personalidade dos sujeitos;

2) Não há diferenças estatisticamente significativas entre os sujeitos das quatro principais posições fraternais (filhos únicos, mais velhos, mais novos e do meio) - variável FRATRIA4 - em qualquer das trinta facetas da personalidade.

\section{Resultados}

O estudo da análise multivariada (GLM) relativo aos 1.142 sujeitos da amostra, considerando os efeitos principais das trinta e duas variáveis independentes (dados sociobiográficos) nas trinta variáveis dependentes (as trinta facetas da personalidade), proporcionou os seguinte resultados:

1) as variáveis FRATRIA4 (filhos únicos, irmãos mais velhos, irmãos mais novos e irmãos do meio), "sexo" (feminino e masculino), "grupo etário" (17 a 20 anos e acima dos 21 anos de idade - os dois grupos etários que exigem normas de cotação diferente no NEO PI-R), "política" (direita, centro, esquerda e independente), "religião" (nenhuma, católica praticante, católica não praticante e outras religiões), "escolas" (número de escolas freqüentadas: abaixo da média, na média e acima da média), "ttdoença" (teve/tem doença e/ou deficiência: nunca teve, teve com menos de 16 anos, teve com mais de 16 anos, teve sempre e sem resposta), "morteir" (morte de irmãos: sem mortes e com mortes), "maevive" (a mãe do sujeito vive ou já morreu), "avópatvi" (a avó paterna vive ou já morreu), "subsmat" (teve ou não substituta materna) e "subspat" (teve ou não substituto paterno) são significativas nos quatro testes 
para a estatística $f$ (i.e. nível de significação $p<0,05$ no Lambda de Wilk's, no traço de Pillai-Bartlett, no traço de Hotelling-Lawley e no Roy's greatest characteristic root);

2) as variáveis "emprego" (nunca trabalhou, começou a trabalhar antes dos 18 anos e começou a trabalhar depois dos 18 anos), "vivecagr" (vive com o agregado familiar: mesmo durante as aulas, apenas nas férias e sem resposta) e "avôpatvi" (o avô paterno vive ou já morreu) apresentam um nível de significação $p<0,05$ apenas no teste Roy's Largest Root.

Isso equivale a dizer que, das trinta e duas variáveis independentes, apenas quinze delas (as doze primeiras mais inequivocamente do que as três últimas) determinam globalmente diferenças na variância dos resultados dos sujeitos nas trinta facetas da personalidade. Ou seja: a significação dos testes multivariados para essas quinze variáveis permite-nos afirmar que, nesse modelo, é pouco provável que as médias dos diversos grupos definidos por essas variáveis sejam iguais.
Mas, embora os resultados multivariados para a FRATRIA4 se mostrem significativos, os resultados univariados indicam-nos que os quatro grupos fraternais categorizados nessa variável só diferem significativamente em seis das trinta facetas da personalidade - três pertencentes ao domínio da Amabilidade (A2, A3, A4), duas ao domínio da Conscienciosidade (C3 e C6) e uma ao domínio da Extroversão (E2) - conforme pode ser observado no Tabela 3.

No intuito de verificarmos quais os grupos da FRATRIA4 eram significativamente diferentes, realizamos o procedimento de comparação múltipla, ou estudo Post Hoc de análise intergrupos, utilizando o teste de Bonferroni. Essas comparações revelaram-nos que as diferenças entre as médias observadas em algumas facetas da personalidade eram estatisticamente significativas $(p<0,05)$, ou seja, existem alguns aspectos dissemelhantes entre as quatro posições fraternais (Tabela 4).

Tabela 3. Resultados univariados para a variável FRATRIA4

\begin{tabular}{|c|c|c|c|c|c|c|c|}
\hline Variável dependente fonte & $\begin{array}{c}\text { Tipo III } \\
\text { Soma dos } \\
\text { quadrados }\end{array}$ & $\mathrm{GL}$ & $\begin{array}{c}\text { Média } \\
\text { quadrática }\end{array}$ & $\mathrm{F}$ & Sig. & $\begin{array}{l}\text { Parâmetro } \\
\text { não centrado }\end{array}$ & $\begin{array}{c}\text { Poder } \\
\text { observado* }\end{array}$ \\
\hline \multicolumn{8}{|l|}{$\overline{\text { FRATRIA4 }}$} \\
\hline $\mathrm{A} 2$ - retidão & 135,344 & 2 & 67,672 & 4,085 &, 017 & 8,170 &, 726 \\
\hline A3 - altruísmo & 72,213 & 2 & 36,107 & 3,024 &, 049 & 6,047 &, 586 \\
\hline A4 - complacência & 147,668 & 2 & 73,834 & 4,212 &, 015 & 8,424 &, 740 \\
\hline C3 - obediência ao dever & 103,984 & 2 & 51,992 & 4,142 &, 016 & 8,284 &, 732 \\
\hline C6 - deliberação & 177,296 & 2 & 88,648 & 4,447 &, 012 & 8,894 &, 764 \\
\hline E2 - gregariedade & 154,874 & 2 & 77,437 & 3,297 &, 037 & 6,593 &, 626 \\
\hline
\end{tabular}

* computado usando $\alpha=0,05$.

Tabela 4. Análise intergrupos (teste de Bonferroni) para a variável FRATRIA4.

\begin{tabular}{|c|c|c|c|c|c|c|c|}
\hline \multirow{2}{*}{$\begin{array}{l}\text { Tipo de } \\
\text { fratria (I) }\end{array}$} & \multirow{2}{*}{$\begin{array}{l}\text { Tipo de } \\
\text { fratria }(J)\end{array}$} & \multirow{2}{*}{$\begin{array}{l}\text { Facetas da } \\
\text { personalidade }\end{array}$} & \multirow{2}{*}{$\begin{array}{l}\text { Diferença entre } \\
\text { as médias (I-J) }\end{array}$} & \multirow{2}{*}{ Erro-padrão } & \multirow{2}{*}{ Sig. } & \multicolumn{2}{|c|}{ Intervalo de confiança de 95\% } \\
\hline & & & & & & Limite inferior & Limite superior \\
\hline Únicos & Mais velhos & A4 - complacência & -1.1567 & .416 & .033 & -2.2556 & $-5.7828 \mathrm{E}-02$ \\
\hline \multirow{4}{*}{ Mais velhos } & Mais novos & $\begin{array}{l}\text { A2 - retidão } \\
\text { A4 - complacência }\end{array}$ & $\begin{array}{l}-1.1455 \\
-1.3080\end{array}$ & $\begin{array}{l}.404 \\
.416\end{array}$ & $\begin{array}{l}.028 \\
.010\end{array}$ & $\begin{array}{r}-2.2141- \\
2.4072\end{array}$ & $\begin{array}{r}-7.6888 \mathrm{E}-02 \\
-.2088\end{array}$ \\
\hline & \multirow[t]{4}{*}{ Do meio } & A3 - altruísmo & .9538 & .311 & .013 & .1312 & 1.7765 \\
\hline & & C3 - obediência ao dever & .97391 & .319 & .014 & .1304 & 1.8173 \\
\hline & & C6 - deliberação & .3490 & .402 & .005 & .2861 & 2.4119 \\
\hline \multirow[t]{3}{*}{ Mais novos } & & N2 - hostilidade & -1.1787 & .408 & .024 & -2.2567 & -.1006 \\
\hline & Do meio & $\mathrm{A} 2$ - retidão & 1.0310 & .367 & .030 & 6.173E-02 & 2.0003 \\
\hline & & A4 - complacência & 1.0270 & .377 & .040 & $2.990 \mathrm{E}-02$ & 2.0241 \\
\hline
\end{tabular}




\section{Discussão}

Uma primeira conclusão a retirar desta análise estatística é a de que a posição na fratria, tal como foi definida pela variável FRATRIA4, é efetivamente um dos aspectos responsáveis pelas variações na personalidade dos sujeitos (a par de outras catorze variáveis sociobiográficas, como vimos acima). A importância da fratria é ainda demonstrada pela significação que a morte de irmãos (que é a variável que mede a existência ou não de mortes na fratria) obtém nesse modelo.

Isto é, os resultados dos testes multivariados permitem-nos concluir que a primeira hipótese nula deste estudo foi estatisticamente rejeitada. Lembramos que ela estabelecia que a posição fraternal não era uma das variáveis que contribuía para a variação na personalidade dos sujeitos.

Em segundo lugar, baseados nos testes univariados, podemos afirmar, igualmente, que a segunda hipótese nula deste estudo foi, igualmente, estatisticamente rejeitada. Ela previa a não existência de diferenças de personalidade entre os sujeitos que ocupam cada uma das quatro principais posições fraternais: únicos, mais velhos, mais novos e do meio.

E, por último, se olharmos os resultados das comparações entre as quatro principais posições fraternais, podemos constatar como alguns desses resultados vão de encontro ao descrito/encontrado por alguns autores. Esses dados podem ser sintetizados e interpretados da seguinte maneira:

1) Os filhos únicos são menos amáveis do que os mais velhos e do que os mais novos: entre os únicos e os mais velhos só na faceta da complacência é que a diferença das médias é estatisticamente significativa; entre os únicos e os mais novos as diferenças situam-se quer na faceta da complacência quer na da retidão.

Se lembrarmos que a faceta da complacência de ora em diante servir-nos-emos das definições das facetas apresentadas no Manual do NEO PI-R (Lima \& Simões, 2000) - tem a ver com a capacidade de aceitação da opinião dos outros, de esquecer e perdoar, não admira que os únicos - dado terem vivido num contexto de exclusividade dentro da família e de, conseqüentemente, terem tido menos oportunidades de se interrelacionar com os pares - se revelem menos complacentes do que aqueles que tiveram irmãos (sejam eles os mais velhos ou os mais novos da fratria), o que se traduz, nomeadamente, numa menor capacidade de partilhar e aceitar a opinião dos outros (Adler, 1912/1993; König, 1958/1996; Toman, 1993).

Quanto à menor retidão dos filhos únicos relativamente aos mais novos (a faceta da retidão mede a capacidade de ser"franco, frontal, sincero e ingênuo ao lidar com os outros"), julgamos que isso pode ter a ver com as mesmas razões apontadas atrás: de um menor desenvolvimento das capacidades relacionais dos filhos únicos relativamente aos sujeitos que têm irmãos, o que os tornaria "emocionalmente mais inexperientes" (König, 1958/1996, p.19) e, por isso, com mais tendência a esconderem a verdade e a não mostrarem os seus verdadeiros sentimentos (que é o que caracteriza os sujeitos com pontuação baixa na faceta retidão).

2) Os mais velhos são mais conscienciosos (isto é, mais obedientes ao dever e mais deliberados), mais altruístas e menos hostis do que os do meio.

Os mais velhos são, unanimemente, vistos como aqueles que mais estritamente aderem aos"padrões de conduta, princípios éticos e obrigações morais" (e isto é, por definição, a faceta obediência ao dever). A sua situação de primogênito da fratria impõe-lhe a responsabilidade de ser o detentor das normas e valores familiares, o que o tornaria mais conservador do que os não primogênitos (Sulloway, 1997; Toman, 1993) e, conseqüentemente, mais deliberado do que esses (a deliberação éa tendência para pensar com cautela, para planificar e para ponderar, antes de agir).

Por sua vez, é de crer que os irmãos do meio que, contrariamente aos mais velhos, têm papéis pouco definidos dentro da família - se tornem mais hostis, isto é, tenham "tendência a experienciar raiva e estados afins, como a frustração e a amargura" (ver faceta da hostilidade, do domínio do Neuroticismo), como reflexo das lutas que travam pela sua identidade e conquista de espaço no seio do grupo familiar. Essa situação pode explicar, também, que os irmãos do meio se mostrem menos altruístas do que os mais velhos (os sujeitos com pontuação baixa na faceta do altruísmo - que pertence ao domínio da Amabilidade - são mais centrados em si próprios e relutantes em envolver-se nos problemas dos outros, enquanto os sujeitos com pontuação elevada revelam uma preocupação ativa pelos outros).

3) Os mais novos são, como já referimos no ponto 1, mais amáveis (nomeadamente: mais retos e complacentes) do que os únicos. São, igualmente, mais retos e complacentes do que os do meio. 
Essas diferenças entre os mais novos e os do meio podem, provavelmente, justificar-se pelas mesmas razões apontadas acima para as dissemelhanças entre estes últimos e os mais velhos: os mais novos têm, tal como os mais velhos e contrariamente aos do meio, uma posição bem definida na fratria, o que lhes permite serem mais frontais e terem menos tendência para manipular os outros através do elogio e da chantagem (alta pontuação na faceta da retidão) e, ainda, para serem menos agressivos, antagônicos, contestadores e competitivos (resultados elevados na faceta da complacência).

\section{Conclusão}

Com esta investigação pudemos confirmar que a posição na fratria é, entre outras variáveis e conjuntamente com elas, uma das que provoca variações (estatisticamente significativas) na personalidade dos sujeitos. Como ficou demonstrado pela marcada interferência que algumas outras variáveis respeitantes à condição/vida dos sujeitos têm na sua personalidade (como o sexo, a idade, algumas perdas significativas, etc.), o lugar único configurado, desde logo, pelas diferentes ordens de nascimento dos irmãos é, apenas, um dos fatores explicativos da diversidade encontrada. Embora importante, a posição fraternal não é tudo como sublinhou, repetidamente, Toman (1959, 1993, 1995), um dos mais profícuos investigadores desse tema.

E também pudemos apurar que são, sobretudo, os aspectos relacionados com a sociabilidade que distinguem significativamente as principais posições fraternais (nomeadamente: as diferenças aparecem em algumas facetas dos domínios da Amabilidade, da Conscienciosidade e do Neuroticismo).

Em síntese, parece inequívoco que o lugar único que cada um de nós ocupa na família determina experiências igualmente únicas que originam vias diferenciadas na construção da personalidade de cada um dos membros. Havendo, todavia, quando estudamos esse aspecto especificamente humano, a necessidade de uma visão circular e aberta à complexidade dos fenômenos relacionais.

\section{Referências}

Adler, A. (1984). Conocimiento del hombre (7a. ed.). Madrid: Editorial Espasa-Calpe. (Originalmente publicado em1926).
Adler, A. (1993). El carácter neurótico (2a. ed.). Barcelona: Ediciones Paidós Ibérica. (Originalmente publicado em 1912).

Almodovar, J. (1986). Construction et économie des liens fraternels. Le Groupe Familial, 111 (4), 2-8.

Arranz Freijo, E. (1989). Psicología de las relaciones fraternas. Barcelona: Editorial Herder.

Assoun, P. -L. (1998). Frères et sœurs: le lien inconscient (Tomo 1). Paris: Economica.

Costa (Jr.), P. T., \& McCrae, R. R. (1992). Four ways five factors are basic. Personality and Individual Differences, 13 (6), 653-665.

Faber, A., \& Mazlish, E. (1995). Jalousies et rivalités entre frères et soeurs. Paris: Éditions Stock.

Fernandes, O. M. (2000). Fratria e personalidade. Tese de doutoramento não-publicada, Universidade de Trás-osMontes e Alto Douro, Vila Real, Portugal.

Fernandes, O. M. (2002). Semelhanças e diferenças entre irmãos. Lisboa: Climepsi Editores.

Fernandes, O. M. (2005). Ser único ou ser irmão. Cruz Quebrada: Oficina do Livro.

Gayet, D. (1993). Les relations fraternelles: approches psychologiques et anthropologiques des fratries. Nêuchatel/ Paris: Delachaux et Niestlé.

Kellerhals, J., \& Roussel, L. (1987). Les sociologues face aux mutations de la famille: quelques tendances des recherches. L'Année Sociologique, 37, 15-44.

König, K. (1996). Frères et soeurs: ordre des naissances dans la constellation familiale (3a. ed.). Chatou: Les Trois Arches. (Originalmente publicado em 1958).

Lima, M. P. (1997). NEO PI-R: contextos teóricos e psicométricos: "OCEAN" ou "iceberg"? Tese de doutoramento não-publicada, Faculdade de Psicologia e de Ciências da Educação, Universidade de Coimbra, Portugal.

Lima, M. P., \& Simões, A. (2000). NEO PI-R: manual profissional. Lisboa: CEGOC-TEA.

Meynckens-Fourez, M. (1999). La fratrie, le point de vue écosystémique. In E. Tilmans-Ostyn \& M. Meynckens-Fourez (Eds.), Les ressources de la fratrie (pp.37-68). Ramonville Saint-Agne: Éditions Érès.

Stein, H.T. (2007). Adlerian overview of birth order characteristics. Disponível em: http://ourworld.compuserve.com/ homepages/hstein/birthord.htm

Sulloway, F. J. (1997). Born to rebel: birth order, family dynamics, and creative lives. New York: Vintage Books.

Toman, W. (1959). Family constellation as a basic personality determinant. Journal of Individual Psychology, 15, 199-211.

Toman, W. (1993). Family constellation: its effects on personality and social behaviour (4th ed.). New York: Springer Publishing.

Toman, W. (1995). Family therapy and sibling position (2nd ed.). Northvale, NJ: Jason Aronson.

Winnicott, D. W. (1989). Tudo começa em casa. São Paulo: Martins Fontes.

Recebido em: 30/1/2007

Aprovado em: 22/5/2007 